\title{
Guns/no guns and the expression of social hostility
}

\author{
DELWIN D. CAHOON and ED M. EDMONDS \\ Augusta College, Augusta, Georgia
}

\begin{abstract}
Forty-eight male college students were exposed either to weapons or to no weapons following positive, neutral, or negative personal evaluation. The dependent measure was aggressiveness as reflected by a specifically constructed Behavior Control Inventory (BCI). The presence or absence of weapons was unrelated to aggressive responding. The results are discussed with respect to the experimental literature and in terms of social policy recommendations related to the weapons effect.
\end{abstract}

Berkowitz and LePage (1967) reported a study in which the presence of firearms appeared to elicit aggressive responding in a laboratory situation. Subsequently, Turner, Layton, and Simons (1975) conducted a field study to see if these findings also applied in a natural setting. Drivers were obstructed by an apparently stalled pickup truck at a traffic light. A rifle in the rear window of the truck, coupled with an aggressive bumper sticker ("Vengeance"), increased horn-honking in obstructed drivers when the driver of the truck was not visible. A study in Sweden by Frodi (1975) found that the "weapons effect" could be demonstrated with Swedish subjects. Page and O'Neal (1977) reported that slides of weapons were also effective in evoking aggression.

However, the conclusion that weapons elicit aggression has not been supported uniformly. Page and Scheidt (1971), in a careful replication of the Berkowitz and LePage (1967) experiment, failed to find a weapons effect, but did find an effect related to subject awareness. Subjects who previously had been exposed to deception in social psychology experiments gave fewer shocks in an aggressive context when guns were present. Turner and Simons (1974) also found that nonapprehensive subjects who were sophisticated with respect to the purpose of the weapons gave fewer shocks. An attempt by Halderman and Jackson (1979) to replicate the horn-honking study of Turner et al. (1975) in a rural community provided no support for the weapons effect. Halderman and Jackson suggested that the weapons effect may be negated when the presence of a rifle in the rear window of a pickup truck is commonplace.

Buss, Booker, and Buss (1972) found no evidence that actually shooting a gun under field conditions was related to aggression measured in the laboratory. Furthermore, in an almost exact replication of the Berkowitz and LePage (1967) study, Buss et al. found

Reprint requests may be sent to Delwin D. Cahoon, Department of Psychology, Augusta College, Augusta, GA 30910. that the presence of weapons significantly decreased shocking in the laboratory situation. Another attempt to replicate the Berkowitz and LePage experiment reported a similar outcome. Ellis, Wienir, and Miller (1971) indicated that there was a trend toward inhibition of aggressive responding when weapons were present.

The studies that have been generally supportive of the weapons effect occasionally have been difficult to interpret. Turner et al. (1975), for example, actually found that male drivers of older vehicles, and female drivers of all vehicles, engaged in more horn-honking when no rifle or bumper sticker was present. Although these results are interpreted as reflecting inhibition produced by the rifle in an aggressive context, other interpretations are obviously possible.

Although the evidence for a weapons effect is conflictual, the hypothesis has had considerable impact upon social policy positions. In an article in Psychology Today, entitled "How Guns Control Us," Berkowitz (1981) advocated stricter gun controls on the basis of his acceptance of the weapons effect. No mention is made of opposing evidence. Also, the American Psychological Association (Mervis, 1982) has taken a position in favor of gun control, a position probably influenced by the literature supportive of the weapons effect.

The evidential basis for the existence of a weapons effect is obviously ambiguous. The present study was an attempt to contribute additional data relevant to this socially important issue.

\section{METHOD}

\section{Subjects}

The subjects were 48 male Augusta College students recruited from introductory psychology and sociology classes. Other than the assurance that the subjects would find participation to be "an interesting experience, no credit or reward was given for involvement in the experiment. Since the experiment was conducted during class time, the students were also excused from class for one 50-min period. 


\section{Procedure}

The subjects were escorted to the Psychology Clinic in groups of 16. Upon entering the clinic, the students passed a closed door labeled "Law Enforcement Seminar" before they entered a classroom-lounge area. Once in the lounge, the subjects were seated in two rows of eight chairs facing one another. The subjects were then each given a number (1 to 16) to wear conspicuously so that they might be identified without referring to their names. The subjects were told that they were involved in a study concerning "first impressions" and that they would be rating an individual in the opposite row. In order to provide an apparent basis for judgment, each subject was asked to state his major and something about his hobbies or interests.

At this point, a specially prepared "First Impressions Inventory" was distributed. A number on each form indicated which individual the subject was to rate. The subject was cautioned not to stare at this person and not to indicate in any other way whom he was evaluating. The instructions for the inventory, which were read aloud, were as follows:

Rate your impressions of the other person in the categories below. It doesn't matter that your impressions are "irrational" or "make no sense." Remember we are interested only in "first impressions" which, while real and important, often cannot be explained rationally. Although your responses are not considered to be confidential, you are encouraged to be completely honest in your rating and to complete each item.

In this manner, first-impression ratings were obtained on a 5-point scale for physical appearance, personal adjustment, honesty, likeability, attractiveness as a work partner, intelligence, and overall first impression.

Following completion of the First Impressions Inventory, the subjects were asked to complete a Social Control Opinion Survey in order to establish a baserate of attitudes concerning the use of punishment in controlling controversial social behaviors. On a 5-point scale ranging from "no punishment" to "severe punishment," the subjects expressed their opinions on murder, marijuana use, rape, drunken driving, child abuse, alcoholism, illegal gambling, selling heroin, misbehavior by school children, shoplifting, thumb-sucking in children, profanity in children, failure to pay debts, sexual immorality, cheating on income tax, "peeping" for sexual excitement, cheating on examinations, bed-wetting, cruelty to animals, violating the speed limit, vandelism, and failure to register for the draft.

At this point, one of the two experimenters left the room and took all of the completed forms with him. After $3 \mathrm{~min}$, he returned and announced that Subjects $1,3,4,7,8,10,13$, and 14 were to be transferred to another room, while Subjects 2, 5, 6, 9, 11, 12, 15 , and 16 were to remain where they were. This assignment assured that none of the subjects who had rated one another were in the same group. The second experimenter then escorted the designated subjects to the room with the sign "Law Enforcement Seminar." Conspicuously displayed on a central table within the room were three handguns (Ruger .22, Berretta .380, Charter Arms . 44 Special) and a 24 -in. police nightstick. The subjects were told that the weapons were demonstration items in a seminar being presented that evening by the College Division of Public Safety. The subjects seemed to accept the presence of the guns and the explanation, and no questions were asked. The subjects were then seated in the eight available chairs, each positioned so that the weapons were clearly visible at all times.

Except for the presence of the guns for one group of subjects, the procedure from this point on was uniform for all subjects. First, the subjects were each given a completed First Impressions Inventory and told that this was the form that had been completed for him earlier in the experiment. Actually, the forms had been prepared by the experimenters and fell into one of three categories: A positive condition, in which the form indicated that the subject's first impression had been very favorable, a negative condition, in which the rated impression was quite unfavorable, and an intermediate neutral condition. After examining what was ostensibly his personal rating for a few minutes, the subject was asked to complete the Behavioral Control Inventory (BCI). The BCI poses 12 hypothetical situations involving misbehavior; the rater can select from among four responses in dealing with the misbehavior. In each item, the person presumed to have misbehaved is presented as the rater who has just evaluated the subject. An illustrative item reads as follows:

You are a college professor who catches the person that has just rated you cheating on a test. What would you do?

1. Call him or her to your office and tell them you will be watching them closely for the rest of the quarter

2. Give them a "zero" on the test but take no further action

3. Fail them in the course

4. Initiate action to have them dismissed from college for academic dishonesty

The BCI thus provided an opportunity to express hostility or aggression toward the individual who had evaluated the rater in terms of a favorable, unfavorable, or neutral first impression. As an instrument, the BCI possesses considerable face validity, and it also was scored by eight psychologists as a validation measure. All of the psychologists were in agreement (100\% concordance) with respect to the punitive ratings of the response alternatives to each item. A split-half reliability coefficient of .83 indicates that the inventory was an acceptably stable measuring device.

Following the completion of the $\mathrm{BCI}$, the subjects were thanked and debriefed concerning the artificial evaluation provided by the First Impressions Inventory.

In summary, each of the subjects was led to believe that he had been evaluated in a favorable, unfavorable, or neutral manner by another person. The subjects in these three conditions were also either exposed to weapons or not so exposed. It was hypothesized that, in accordance with the weapons effect, the subjects in the gun condition would express more hostility than the subjects in the no-gun condition. It was further hypothesized that the expression of hostility would vary depending upon the kind of firstimpression feedback (positive, negative, or neutral) provided the subject.

\section{RESULTS AND DISCUSSION}

A $2 \times 3$ analysis of variance classified by guns-no guns and the three first-impression feedback conditions (positive, neutral, or negative) indicated that the weapons main effect and the interaction effect were not significant as measured by the BCI. The feedback main effect on the BCI was significant $[F(2,42)=5.48, p<.01]$, indicating that the positivefeedback condition produced significantly more positive responses than did the neutral-feedback condition $[\mathrm{t}(30)=2.89, \mathrm{p}<.01]$. The differences between neutral and negative feedback and between positive and negative feedback were not significant. The means for the three feedback conditions were 19.68 (positive), 24.31 (neutral), and 22.31 (negative).

In order to determine whether weapons differentially affected the responses of students who initially advocated punishment and the responses of less punitive subjects, the BSI scores of students who scored above the mean on the Social Control Opinion Survey were compared with the BSI scores of those students who scored below the mean. There were no sig- 
nificant differences between the BSI ratings of high and low advocates of punishment as a function of the presence or absence of weapons.

The results of the study do not support the existence of a weapons effect under the conditions described. This outcome is partially or completely consistent with several other reports, including those by Buss et al. (1972), Ellis et al. (1971), Page and Scheidt (1971), and Turner and Simons (1974).

Perhaps other variables obscured the expression of the weapons effect. Subject sophistication, demand awareness, evaluation apprehension, social status, and weapon familiarity have all been suggested as attenuating variables in the studies cited above.

Another explanation for the inconsistency of the weapons effect is that it may result from a specific interpretation of general arousal. As Schachter and Singer (1962) demonstrated, an aroused bodily state can be interpreted in a number of ways depending upon situational cues and the expectations of the subject. If weapons were merely generally arousing, their presence would lead to an increase in aggressiveness only if the arousal were viewed as anger. Under other circumstances, for example, among the participants in an eagerly awaited hunting trip, the presence of guns might actually increase the frequency of friendly and helpful behavior if the arousal were interpreted as excitement and anticipation.

It might be argued, of course, that the subjects in the present experiment were not actually angered by the negative first-impression feedback. However, the significant difference on the BSI for subjects in the positive and neutral conditions suggests that some negative arousal did occur.

The absence of a significant difference on the BSI between the negative-feedback condition and the other feedback conditions may be interpreted as being consistent with several reports in the literature. For example, Page and Scheidt (1971) found that subjects who were acquainted with deception in psychology experiments gave fewer shocks in the presence of guns. This is interpreted as a demonstration of what Masling (1966) termed the "screw you" effect, in which aware subjects resist compliance with the perceived aims of the experiment. In the present experiment, the negative first-impression feedback may have been unbelievable for some subjects, resulting in partial awareness of the purpose of the experiment and leading to noncompliance. In addition, if the negative-feedback condition were recognized as deceptive, anger would probably not result from the evaluation and aggression would not be elicited. These possibilities are supported by one subject's spontaneous comment that he knew the feedback was false because his presence in college indicated that he was intelligent rather than stupid. For those subjects who accepted the negative feedback as genuine, response suppression might have occurred for a different reason. Turner et al. (1975), in the horn-honking experiment described earlier, found that male drivers of older vehicles, and females, emitted fewer honks in the presence of a rifle and an aggressive bumper sticker. This is interpreted as inhibition of aggressive responding (horn-honking) toward a higher status person. If subjects in the present study accepted the negative evaluation as authentic, they may have felt socially devalued and rejected as well as angry, resulting in reduced aggressive responding toward the evaluator. Although these explanations are obviously post hoc, the fact that a difference was found between the positive- and neutral-feedback conditions suggests that the negative first-impression feedback may simply have been so extreme that the expression of aggressiveness was inhibited. Furthermore, it should be noted that anger may not always be a necessary condition for the expression of the weapons effect (Frodi, 1975).

The most parsimonious interpretation of the experiment seems to be that the weapons effect is an exceedingly weak varible evidenced only under special conditions. In fact, the results of the present study, as well as those of numerous other studies (e.g., Buss et al., 1972; Ellis et al., 1971; Page \& Scheidt, 1971; Turner \& Simons, 1974) indicate that the role of weapons in inhibiting violence seems to be at least as well documented as a weapons effect leading to aggression. A report in Psychology Today (Corey, 1979) also supported the possibility that weapons may inhibit violence in natural settings. The article, based upon data assembled by the Institute for Law and Social Research, indicated that criminals armed with guns are less likely to harm their victims than are robbers who carry knives, clubs, tire irons, or other weapons. The report also documents that gunwielding robbers are less likely to harm others than are criminals who are unarmed.

In summary, the present research is consistent with studies that have failed to demonstrate the existence of a weapons effect. In view of the conflictual, if not contradictory, results in this important area, it seems prudent for psychologists to avoid further public policy recommendations based upon an apparently elusive variable. To do otherwise may serve to weaken the credibility of psychology as a data resource with respect to social issues.

\section{REFERENCES}

Berkowitz, L. (1981, June). How guns control us. Psychology Today, pp. 11-12.

BerkowITZ, L., \& LePAGE, A. (1967). Weapons as aggression-eliciting stimuli. Journal of Personality and Social Psychology, 7, 202-207.

Buss, A., Booker, A., \& Buss, E. (1972). Firing a weapon and aggression. Journal of Personality and Social Psychology, 22, 296-302. Cory, C. T. (1979). Newsline. Psychology Today, pp. 21.

Ellis, D. P., Weiner, P., \& Miller, L. (1971). Does the trigger pull 
the finger? An experimental test of weapons as aggression-eliciting stimuli. Sociometry, 34, 453-465.

Frodi, A. (1975). The effect of exposure to weapons on aggressive behavior from a cross-cultural perspective. International Journal of Psychology, 10, 283-292.

Halderman, B. T., \& JACKson, T. T. (1979). Naturalistic study of aggression: Aggressive stimuli and horn-honking: A replication. Psychological Reports, 45, 880-882.

MASLING, J. (1966). Role-related behavior of the subject and psychologist and its effect upon psychological data. In D. Levine (Ed.), Nebraska Symposium on Motivation (Vol. 14, pp. 67-103). Lincoln: University of Nebraska Press.

Mervis, J. (1982, March). Council acts on building, budget, new programs. APA Monitor, 13, pp. 40.

PAGe, D., \& O'Neal, E. (1977). "Weapons effect" without demand characteristics. Psychological Reports, 41, 29-30.
PAge, M., \& ScheIDT, R. (1971). The elusive weapons effect: Demand awareness, evaluation apprehension, and slightly sophisticated subjects. Journal of Personality and Social Psychology, 20, 304-318.

SCHACTER, S., \& Singer, J. E. (1962). Cognitive, social and physiological determinants of emotional states. Psychological Review, 69, 379-399.

TuRner, C. W., Layton, J. F., \& Simons, L. S. (1975). Naturalistic studies of aggressive behavior: Aggressive stimuli, victim visibility, and horn-honking. Journal of Personality and Social Psychology, 31, 1098-1107.

TURNER, C. W., \& Simons, L. S. (1974). Effects of subject sophistication and evaluation apprehension on aggressive responding to weapons. Journal of Personality and Social Psychology, 30, 341-348.

(Manuscript received for publication February 13, 1984.) 